\title{
STUDENTS' SATISFACTION LEVEL TOWARDS ONLINE LEARNING COMPARED TO TRADITIONAL CLASSROOM FOR ENGLISH SUBJECT
}

\author{
${ }^{1}$ Glenn Ponto \\ Universitas Internasional Batam \\ popongaulz@hotmail.com \\ ${ }^{2}$ Nurlaily \\ Universitas Internasional Batam \\ nurlaily@uib.ac.id
}

\begin{abstract}
Amidst the COVID-19 pandemic, schools and universities in Indonesia are being closed down temporarily by the government. A shift from a traditional classroom has emerged. Online learning starts becoming the policy from the government until the COVID-19 issue ends. This study aims to examine the students' satisfaction level in English subject at Universitas Internasional Batam towards online learning as opposed to traditional classrooms. Student satisfaction is an important parameter since it shows how they perform and engage in class. This research was conducted using a quantitative method. The sample of this study will be second-semester students who took English 2 subject. The data collection was done through google form questionnaires. The results of this study are expected to be a baseline for future improvement in online learning.
\end{abstract}

Keywords: Students Learning Satisfaction, Online Learning, Traditional Learning, English Teaching and Learning

\section{INTRODUCTION}

The COVID-19 Pandemic has made it almost impossible for people around the world to exercise their daily activities, and this includes students who are attending university. A lockdown has been mandated almost worldwide to prevent further spread of this pandemic. This phenomenon affects students greatly as they are incapable of leaving their homes to join classes in their respective universities. Traditional classrooms begin to fade from universities as the situation worsens, and online-based learning becomes a huge surge in usage during this time. The online learning is conducted to overcome the limitations between teachers and students even though there are still varied responses from both parties.

Satisfaction is the measure of pleasure that an individual has towards a certain object or activity, which in this case is education (Horzum, 2015). Student satisfaction is thought to have a high correlation with their performance in a specific class. According to Swan (as cited in Gray \& DiLoreto, 2016), it is believed that student satisfaction will skyrocket in proportion to the activeness of the teacher and fellow learners. Traditional class is a form of class in which teachers and students are gathered in a classroom and conduct their studies in a face-to-face setting. It is commonly found everywhere all over the world and is the preferred way of teaching by many teachers. Online learning is a type of teaching that relies on remoteness or non-physical meeting of the teachers and students (Bartley \& Golek, 2004; Evans 
\& Haase, 2001, as cited in Nguyen, 2015). Online learning relies on the internet as physical interaction is non-existent. Tools of online teaching range from online classroom tools such as Blackboard to skype video calls between teachers and students.

Napitupulu et al. (2016) conducted a quantitative study on the level of user satisfaction with the quality of existing service facilities at XYZ University. The results showed a low level of student satisfaction. There was a significant difference between the perceptions and expectations of users. It was clear that the quality of campus service facilities shall be improved as it is still far below user expectations.

On the other hand, Hossain, et.al. (2019) analyzed the factors that affected students' satisfaction at private and public universities in Bangladesh. The research was employed using a quantitative method. From the findings, it was shown that female students were not satisfied with their institutions as much as the male students. Moreover, students from the suburban area and middle-class families were more pleased with the university than any other participants. The students' satisfaction was influenced by many factors such as teachers' expertise, curriculum design, facilities, infrastructure, and also some demographic variables.

Different from the previous research, Martin \& Bolliger (2018) surveyed to examine students' perceptions of diverse engagement strategies used in online courses. The research followed Moore's interaction framework of engagement: learner-to-learner, learner-to-instructor, and learner-to-content engagement strategies. The results of the research emphasized on how engagement strategies supporting interactions with instructors were acceptable more than strategies for interactions with learning material and other learners.

To comprehend the implementation of online learning, the authors aimed to examine the level of satisfaction of second-semester Universitas Internasional Batam (UIB) students who enrolled in English 2 subject. Although online learning has had traction in recent years, numerous researchers have doubted its effectiveness compared to a traditional classroom (Jabeen \& Thomas, 2015). The effectiveness of a classroom setting will most likely affect students' satisfaction level towards it. A student may find it difficult to grasp the concept of online learning if they are not familiar with computers, which will then negatively affect their satisfaction level. Other students, however, find online-based learning to be a more ideal way for them to learn. These aspects are imperative as the measure of accomplishment of online-based learning depends on user satisfaction (Hamutoglu et al., 2018). Ultimately, the authors expect that the results of this study can be employed as a baseline for the improvement of upcoming UIB online basedlearning classes to achieve a better learning experience for students of UIB.

\section{METHOD}

\section{Research Method}

This research employed a quantitative method, with a focus on survey design. Quantitative research is defined as research with an emphasis on data and survey designs. A survey design enlightens researchers with a numerical depiction of a tendency, attitude, and/or view of a sample (Creswell, 2014). The data used in this research were data in the form of numbers to show the level of satisfaction of the students toward online learning. 


\section{Respondents}

The participants of this study were $2^{\text {nd }}$ semester students of UIB undertaking English 2 subject class. There were 61 students in total from different classes which each class consisted of 30 and 31 respectively. The students have previously taken English 1 subject with traditional learning. However, the implementation of online learning began in the second semester.

\section{Instruments}

The data collection stage of this study was conducted through Google form questionnaires which were going to be sent out to the participants. The gathered data were processed and analyzed to illustrate the satisfaction level and perceived effectiveness of online class from students' point of view. The questions that appeared on the Google form mostly inquired about students' stance towards online-based learning perceiving their satisfaction towards online classes.

\section{Procedures}

In the data collection, students joined online classes for English 2 subject for 5 meetings. After that, they were asked to fill out a questionnaire that had been uploaded on Google form. All questions related to the level of satisfaction with the implementation of online learning. After the data were collected, the results were categorized and analyzed following the types of questions, namely yes/no questions, multiple-choice questions, and scale questions. The data from each category were shown in the form of charts to display the level of satisfaction.

\section{RESULTS AND DISCUSSION}

The questionnaire distributed to the participants of the study encompasses three question types, namely: yes/no questions, multiple-choice questions, and lastly scale question, with the degree of 1 to 4 , avoiding a middle number in hopes of getting a more precise measurement. There were two to three questions in each type of questionnaire mentioned previously. The numbers of participants given the questionnaire were 61 students combined from two separate classes, with the number of students in each class being 30 and 31 respectively. The result of the questionnaire is elaborated as follows:

Figure 1. Have you experienced online learning previously?

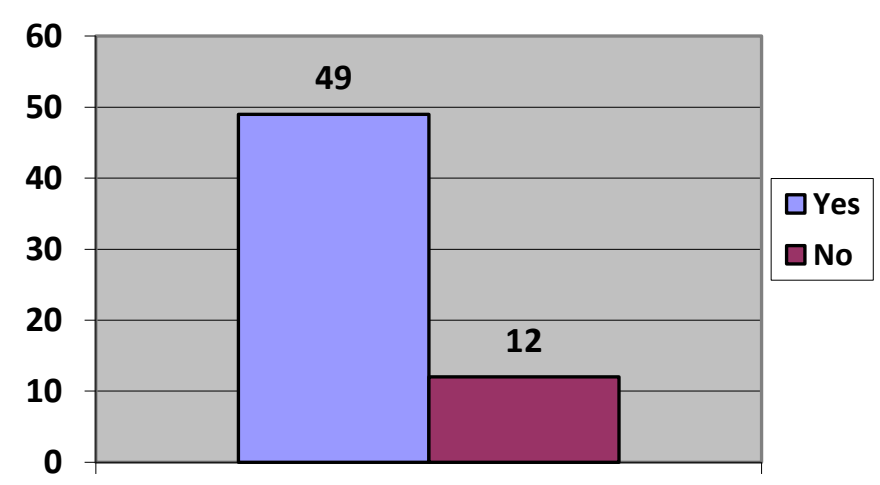


As shown in figure 1, the number of participants that previously engaged in an online lesson before to this study far exceeds the ones that did not, with 49 students responding yes and only a meager 6 with no. It means that almost every participant in this study will be able to contribute positively to this study.

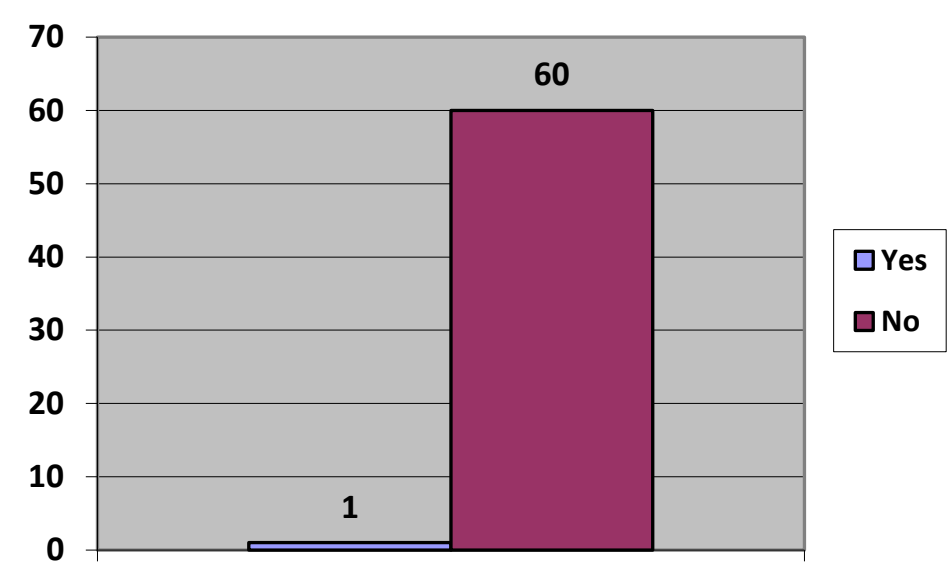

Figure 2. Do you prefer online learning to a face-to-face meeting?

The question in figure 2 intends to figure out students' preferences regarding the online class. Surprisingly, 60 students answered no, which leaves only a single student who prefers online class. This number is certainly alarming, as it means that the participants have bias towards face-to-face learning. The reason for this result will be explained in the following section.

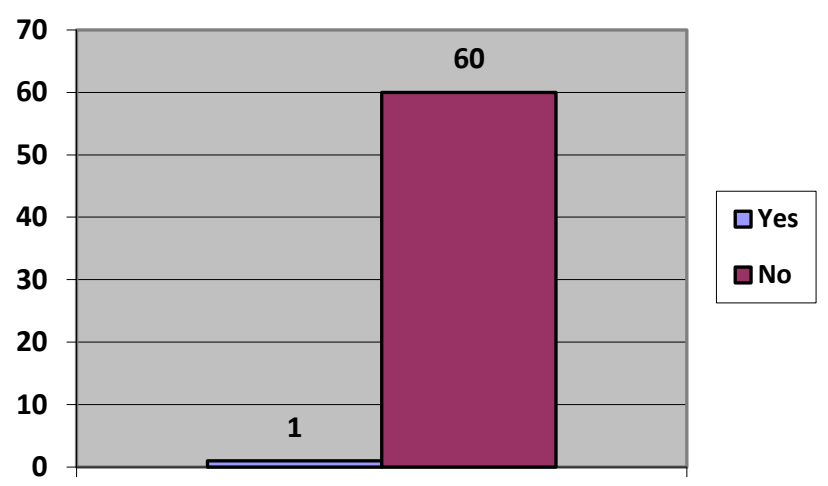

Figure 3. Do you think that online learning is superior compared to a face-to-face meeting?

After observing figure 2, the result of figure 3 should not come as a surprise. This data reinforces the previous figure. This figure, which question was "do you think that online learning is superior compared to a face-to-face meeting?" has an identical result to that of figure 2, which is 1 to 60 in favor of no. The information that should be taken from this figure is that almost every participant views onlinelearning as being inferior to face-to-face meetings, which could very well be the reason they are not in favor of online learning. 
In the following section, Figures $4-7$ cover the multiple choices section of the questionnaire. This section of the questionnaire is aimed at the students' opinions and current stance on online classes as it stands.

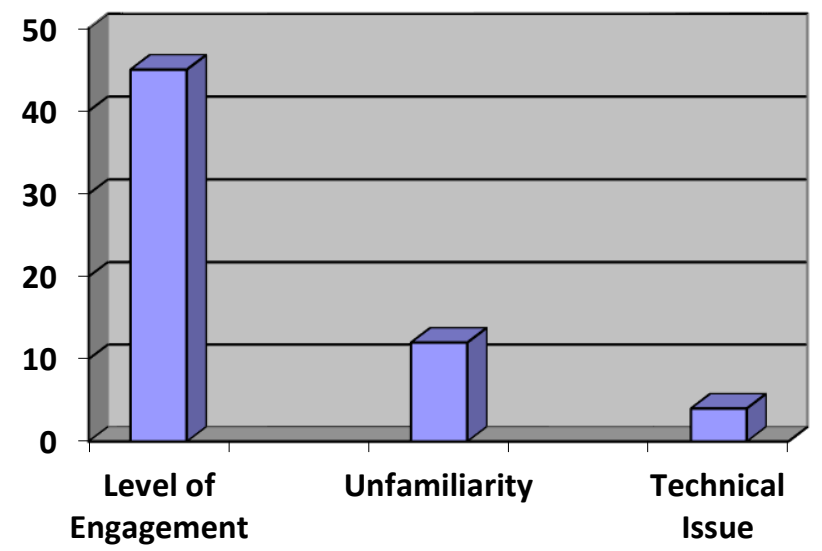

Figure 4. What problems do you constantly face when engaging in an online class?

The majority of the students think that the number one problem with online classes is the level of engagement, with 45 votes. On the opposite end of the spectrum, unfamiliarity and technical issue such as bad internet connection or being technically illiterate are few and far between, with 12 and 4 votes respectively. It is safe to assume that students that participated in filling out the questionnaire do not find online classes providing them with a satisfactory level of engagement to meet their standard.

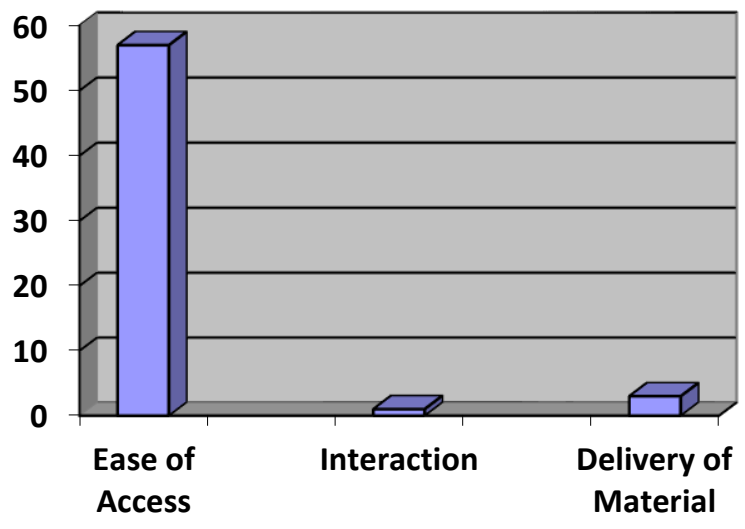

Figure 5. Name an advantage that an online class offers

Figure 5 is intended to inquire about the participants' opinions on the advantage of an online class. Ease of access is the option with the most votes at 57, while interaction accumulates 1 vote and delivery of material at 3 votes. This data shows that students are at the very least positive towards an aspect of online learning, namely the practicality of it. This may be caused by the participants owning the 
required tool for online classes and are comfortable with it, such as a personal laptop and a good internet connection.

The last part of the questionnaire which is a scale-based question will be presented in the following part. The questions in this section are intended to conclude the questionnaire with questions that summarizes the students' satisfaction level with online learning in a general sense.

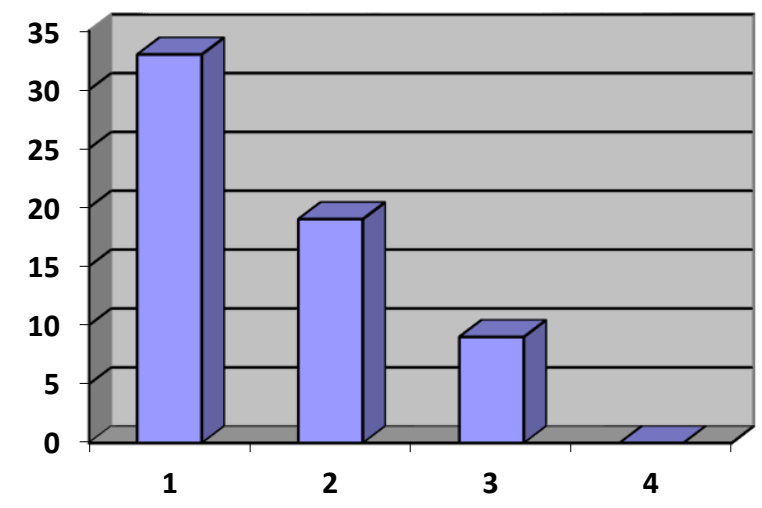

Figure 6. I am satisfied with UIB's Online Class currently.

Predictably, from the answers found in the previous sections, the most votes for the satisfaction level of participants towards online learning is at 1 , which has 33 votes. 19 voted 2 on the scale and 9 voted 3, which leaves 4 with no votes. This answer comes as no surprise as we have established that the participants are more biased against online learning.

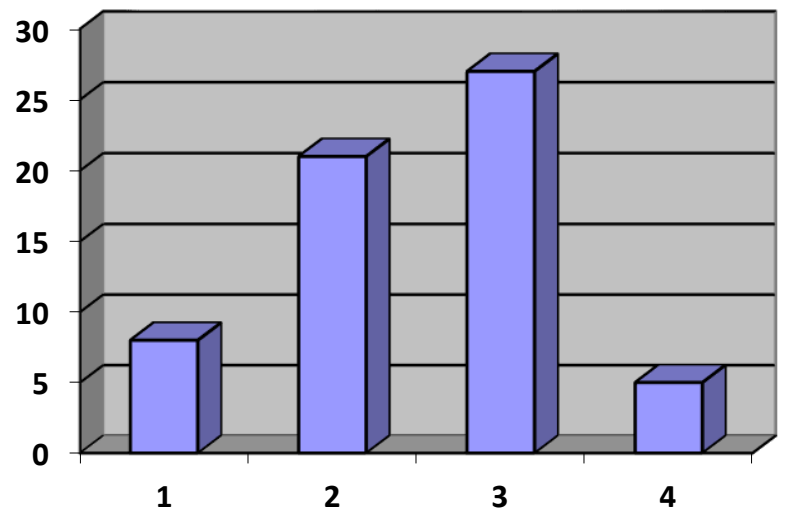

Figure 7. I would look forward to UIB integrating more online classes in the future.

Figure 7 offers us an interesting answer. The number of votes that have the highest value is 3 at 27 votes, which is slightly surprising. 8 votes are for 1, 21 for 2 , and 5 votes for 4 on the scale. This clearly shows that although students are not satisfied with online classes that UIB provides in the present, they are somewhat hopeful and eagerly anticipating an improvement moving forward in regards to UIB online classes. 


\section{CONCLUSION}

After a thorough analysis of the data obtained from the questionnaire, it is concluded that the current online classes in UIB were not satisfactory and up to the standards of the students. That being said, some students are hopeful that UIB will improve their online classes moving forward. The authors suggest that UIB's lecturers need to find ways to increase the level of engagement in online classes, as it is the aspect that most students find lacking in the online classes they attend. One method of driving towards this goal is by designing an online class with a problembased learning approach in mind since it inherently improves students' engagement (Gündüz et al., 2016), which is the area that is lacking in this scenario. Lastly, the authors would like to emphasize on the significance of engagement since interactions between students and instructors lead to an elevated learning outcome and experience as a whole (Goh et al., 2017).

\section{REFERENCES}

Creswell, J. W. (2014). Research design: qualitative, quantitative, and mixed methods approaches4th ed. SAGE Publications, Inc.

Goh, C. F., Leong, C. M., Kasmin, K., Hii, P. K., \& Tan, O. K. (2017). Students' experiences, learning outcomes and satisfaction in e-learning. Journal of ELearning and Knowledge Society, 13(2), 117-128. https://doi.org/10.20368/1971-8829/1298

Gray, J. A., \& DiLoreto, M. (2016). The effects of student engagement, student satisfaction, and perceived learning in online learning environments. NCPEA International Journal of Educational Leadership Preparation, 11(1), 98-119.

Gündüz, A. Y., Alemdağ, E., Yaşar, S., \& Erdem, M. (2016). Design of a problembased online learning environment and evaluation of its effectiveness. Turkish Online Journal of Educational Technology, 15(3), 49-57.

Hamutoglu, N. B., Gemikonakli, O., Savasci, M., \& Gultekin, G. S. (2018). Development of a Scale to Evaluate Virtual Learning Environment Satisfaction. International Journal of Assessment Tools in Education, 5(2), 201-222. https://doi.org/10.21449/ijate.345150

Horzum, M. B. (2015). Interaction, structure, social presence, and satisfaction in online learning. Eurasia Journal of Mathematics, Science and Technology Education, 11(3), 505-512. https://doi.org/10.12973/eurasia.2014.1324a

Jabeen, S. S., \& Thomas, A. J. (2015). Effectiveness of Online Language Learning. In Proceedings of the World Congress on Engineering and Computer Science (Vol. 1). Retrieved April 16, 2020, from

http://www.iaeng.org/publication/WCECS2015/WCECS2015_pp297-301.pdf

Hossain, M. E., Hoq, M. N., Sultana, I., Islam, R., \& Hassan, Md. Z. (2019) Determinants of Students' Satisfaction at Higher Educational Institution in Bangladesh: Evidence from Private and Public Universities. Attarbawiy: Malaysian Online Journal of Education. Vol. 3, No.1, 49-58

Martin, F. \& Bolliger, D.U. (2018). Engagement matters: Student perceptions on the importance of engagement strategies in the online learning environment. Online Learning 22(1), 205- 222. https://doi.org/10.24059/olj.v22i1.1092. 
Napitupulu, D., Rahim, R., Abdullah, D., Setiawan, M. I., Abdillah, L. A., Ahmar, A. S., ... \& Pranolo, A. (2018). Analysis of Student Satisfaction Toward Quality of Service Facility. In Journal of Physics: Conference Series (Vol. 954, No. 1, p. 012019). IOP Publishing.

Nguyen, T. (2015). The Effectiveness of Online Learning: Beyond No Significant Difference and Future Horizons. MERLOT Journal of Online Learning and Teaching, 11(2), 309-319. 